\title{
Removal of Fluoride from Drinking Water Using Modified Immobilized Activated Alumina
}

\author{
Aneeza Rafique, M. Ali Awan, Ayesha Wasti, Ishtiaq A. Qazi, and Muhammad Arshad \\ Institute of Environmental Science and Engineering, School of Civil and Environmental Engineering, \\ National University of Sciences and Technology, Sector H-12, Islamabad 44000, Pakistan \\ Correspondence should be addressed to M. Ali Awan; ali.awan@mail.com
}

Received 25 June 2012; Accepted 14 August 2012

Academic Editor: A. V. Tatarinov

Copyright (c) 2013 Aneeza Rafique et al. This is an open access article distributed under the Creative Commons Attribution License, which permits unrestricted use, distribution, and reproduction in any medium, provided the original work is properly cited.

\begin{abstract}
The study describes the removal of fluoride from drinking water using modified immobilized activated alumina (MIAA) prepared by sol-gel method. The modification was done by adding a specific amount of alum during the sol formation step. The fluoride removal efficiency of MIAA was 1.35 times higher as compared to normal immobilized activated alumina. A batch adsorption study was performed as a function of adsorbent dose, contact time, stirring rate, and initial fluoride concentration. More than $90 \%$ removal of fluoride was achieved within 60 minutes of contact time. The adsorption potential of MIAA was compared with activated charcoal which showed that the removal efficiency was about $10 \%$ more than the activated charcoal. Both the Langmuir and Freundlich adsorption isotherms fitted well for the fluoride adsorption on MIAA with the regression coefficient $R^{2}$ of 0.99 and 0.98 , respectively. MIAA can both be regenerated thermally and chemically. Adsorption experiments using MIAA were employed on real drinking water samples from a fluoride affected area. The study showed that modified immobilized activated alumina is an effective adsorbent for fluoride removal.
\end{abstract}

\section{Introduction}

Fluoride is present in ground water coming either from natural sources like weathering and volcanic processes or from wastewater of industries like fertilizer, glass, ceramic, brick, iron works, and electroplating [1]. Fluoride has both beneficial and harmful effects on the human health depending upon its level. Among the beneficial effects of fluoride in human body, strengthening of bones and prevention from tooth decay are significant. The permissible limit of fluoride in drinking water is $1.5 \mathrm{mg} / \mathrm{L}$ according to the National Standards for Drinking Water Quality of Pakistan [2] and the World Health Organization [3]. Above this limit, fluoride can lead to various diseases such as skeletal and dental fluorosis, brittle bones, cancer, infertility, brain damage, Alzheimer's syndrome, and thyroid disorder [4].

The United Nations Environmental Program (UNEP) estimates that the numbers of individuals affected by fluorosis are in the tens of millions across 25 countries in both developed and developing nations [5]. A number of such cases have been identified in Pakistan where people suffered from harmful diseases due to industrial discharge of fluorides. In July 2000, a tragic situation was reported in Manga Mandi area (near Lahore, Punjab) where level of fluoride reached up to $20 \mathrm{mg} / \mathrm{L}$ in drinking water that led to the bone and teeth deformities in local people [6].

The techniques available for defluoridation include coagulation-precipitation, membrane process, ion exchange, and adsorption processes. Although coagulation-precipitation (also known as Nalgonda technique) is an effective and cheap method but its main disadvantage is the generation of harmful waste products. The membrane process is mainly the reverse osmosis technique but it requires high maintenance cost due to fouling, scaling, and degradation of membrane. Similarly, the ion exchange process is very costly [7]. The adsorption method is considered more appropriate for defluoridation due to its simplicity, effectiveness, and economic viability [8].

The important adsorbents that have been tested for the fluoride removal include activated alumina [9], activated 
charcoal [10], zeolite [11], biosorbents [12], and nanosorbents [13]. Activated charcoal is considered as a universal adsorbent because of its applications and viability. Tembhurkar and Dongre studied the removal of fluoride using activated charcoal [14]. Activated alumina is also an efficient adsorbent for fluoride removal from drinking water but it has limited regeneration capacity and slow rate of adsorption [15].

Several studies have been conducted to increase the efficiency of activated alumina for defluoridation. In a study, alum impregnated activated alumina was used to remove fluoride from drinking water with the removal efficiency of $99 \%$ at $\mathrm{pH} 6.5$ [16]. Similarly, another study reports the adsorption equilibrium and kinetics of fluoride removal using sol-gel-derived activated alumina adsorbent [17]. In this study, calcium oxide and manganese oxide coating were done on sol-gel-derived activated alumina to enhance its fluoride removal efficiency.

The main challenge encountered during the adoption studies is the separation of adsorbent after use from water samples. Generally, filtration is employed for the separation of powdered adsorbents. The aim of the present study was to prepare an immobilized adsorbent in the form of granules that could easily be separated from water without undergoing filtration and centrifugation processes. For this purpose, solgel method has been adopted [18] to prepare immobilized activated alumina with uniform surface properties. The immobilized activated alumina has further been modified by adding alum to enhance its adsorption capabilities. The modified immobilized activated alumina (MIAA) was tested for the treatment of water from fluoride affected Manga Mandi area (near Lahore, Pakistan).

\section{Materials and Methods}

2.1. Materials. Chemicals used in the present study include aluminum tri-sec butoxide (Merck, Germany), activated charcoal (Acros Organics, USA), paraffin oil (MP Biomedicals, LLC Germany), ammonia solution (Burdick and Jackson, Germany), nitric acid (Panreac, Spain), alum, and sodium fluoride $\mathrm{NaF}$ (Merck, USA).

2.2. Preparation of Immobilized Adsorbent. For the preparation of adsorbent, sol-gel method of activated alumina [19] was employed with some modifications. The modified boehmite sol was prepared by dissolving drop-wise $100 \mathrm{~mL}$ aluminum tri-sec butoxide in $300 \mathrm{~mL}$ distilled water at $75^{\circ} \mathrm{C}$ on a hot plate and adding appropriate amount $(10 \mathrm{~g})$ of alum. In order to find out an appropriate alum dose, several boehmite sols were prepared by varying the amount of alum additive from $5 \mathrm{~g}$ to $25 \mathrm{~g}$. As $10 \mathrm{~g}$ of dose gave maximum fluoride removal efficiency (85\%) and considered as appropriate amount of additive. After dissolution, the solution was heated at $90^{\circ} \mathrm{C}$ for one hour and $15 \mathrm{~mL} 1 \mathrm{M} \mathrm{HNO}_{3}$ was added in the slurry. The slurry was refluxed (in a closed vial) in a water bath at $90^{\circ} \mathrm{C}$ for 10 hours to obtain stable modified boehmite sol. The sol was then heated in a petri dish at $40^{\circ} \mathrm{C}$ in an electric oven. The gel was dispensed drop-wise with the help of a syringe (without needle) in the ammonia solution that had a top layer of paraffin oil. The droplets were left in the ammonia solution for 45 minutes in order to turn them into solid granules. The granules were washed thoroughly by distilled water and ethyl alcohol, dried, and calcined at $450^{\circ} \mathrm{C}$ for three hours to obtain modified immobilized activated alumina (MIAA). For each batch adsorption experiment, a fresh adsorbent was prepared as the stated amount is enough for one batch test.

The scanning electron microscope (JEOL JSM-6460, Japan) analysis was performed in order to check the surface of immobilized activated alumina before and after adsorption.

2.3. Adsorption Study. Fluoride adsorption experiments were conducted in order to determine the efficiency of adsorbent and the effect of controlling parameters like dose, contact time, and stirring rate. The stock solution of $5 \mathrm{mg} / \mathrm{L}$ of fluoride was prepared by dissolving $0.011 \mathrm{~g}$ of reagent grade $\mathrm{NaF}$ in $1000 \mathrm{~mL}$ distilled water. All adsorption experiments were carried out in a $250 \mathrm{~mL}$ conical flask with $100 \mathrm{~mL}$ test solution at room temperature $\left(20 \pm 1^{\circ} \mathrm{C}\right)$ using a mechanical shaker. The adsorption experiments were performed at $\mathrm{pH}$ $=7$ and at $20 \pm 1^{\circ} \mathrm{C}$ only in order to be as close as possible to natural drinking water conditions for fluoride removal. Fluoride ion concentration was measured using both spectrophotometer (DR 2010, Hach, USA) and ion selective electrode (Ion meter Model 25, Hach, USA).

The effect of adsorbent dose of adsorbent on fluoride removal was studied by varying the dose from 0.5 up to $20 \mathrm{~g} / \mathrm{L}$ in test solutions containing initial fluoride concentration, $5 \mathrm{mg} / \mathrm{L}$. In order to determine the equilibrium adsorption time, the flasks containing fluoride test solutions $(5 \mathrm{mg} / \mathrm{L})$ and optimum adsorbent dose were agitated on the shaker for periods of $5,15,30,45,60,75,90$, and 120 minutes. Similarly, for the determination of optimum stirring rate, the flasks containing fluoride test solutions $(5 \mathrm{mg} / \mathrm{L})$ and optimum adsorbent dose were agitated on the shaker by changing stirring rate from 50 to $250 \mathrm{rpm}$. The effect of varying fluoride concentration on adsorption was also studied by changing fluoride concentration from 0.5 to $12 \mathrm{mg} / \mathrm{L}$ and employing optimum adsorption conditions. All adsorption tests were run in triplicate to check the precision among the results.

The specified amount of fluoride adsorbed $q_{e}(\mathrm{mg} / \mathrm{g})$ was calculated as follows:

$$
q_{e}=\frac{C_{i}-C_{s}}{m},
$$

where $C_{i}$ is the initial fluoride concentration $(\mathrm{mg} / \mathrm{L}), C_{s}$ is the residual fluoride concentration at equilibrium $(\mathrm{mg} / \mathrm{L})$, and $m$ is the mass of adsorbent in test solution $(\mathrm{g} / \mathrm{L})$.

To compare the efficiency of MIAA, activated charcoal was chosen as standard. All adsorption tests described above were performed again using activated charcoal adsorbent.

2.4. Isotherm Study. The relationship between the amount of substance adsorbed and its concentration in equilibrium solution at constant temperature is called adsorption isotherm. In the present study, the Langmuir and Freundlich isotherms were used to explain the adsorption phenomenon. 
The Freundlich equation

$$
\log q_{e}=\frac{1}{n} \log C_{S}+\log K_{f},
$$

where $q_{e}(\mathrm{mg} / \mathrm{g})=$ amount of fluoride adsorbed per unit mass of adsorbent, $C_{s}(\mathrm{mg} / \mathrm{L})=$ equilibrium concentration of fluoride, and $K_{f}=$ adsorption capacity, $1 / n=$ adsorption intensity.

The values of $K_{f}$ and $1 / n$ were directly obtained from intercept and slope of the linear plot between $\log q_{e}$ and $\log C_{s}$.

The Langmuir isotherm equation

$$
\frac{C_{S}}{q_{e}}=\frac{C_{s}}{V_{m}}+\frac{1}{K V_{m}},
$$

where $q_{e}(\mathrm{mg} / \mathrm{g})=$ amount of fluoride adsorbed per unit mass of adsorbent, $C_{s}(\mathrm{mg} / \mathrm{L})=$ equilibrium concentration of fluoride, $K=$ adsorption capacity, and $V_{m}=$ energy of adsorption.

The values of $K$ and $V_{m}$ were directly obtained from intercept and slope of the linear plot between $q_{e}$ and $C_{s}$.

\subsection{Regeneration and Actual Water Sample Treatment.} Regeneration of the MIAA was done both thermally and chemically. For thermal treatment, the used adsorbent was heated in a muffle furnace at $450^{\circ} \mathrm{C}$ for 30 minutes. In case of chemical regeneration, the used MIAA was soaked in $0.1 \mathrm{M} \mathrm{NaOH}$ solution for two hours. The adsorbent was then washed with distilled water until the washed water $\mathrm{pH}$ became neutral. The regenerated MIAA was tested for the removal of fluoride from test solutions of initial fluoride concentration, $5 \mathrm{mg} / \mathrm{L}$. In this regard, 5 regeneration cycles followed by fluoride removal tests were carried out in succession.

MIAA was also studied for its fluoride removal capabilities from actual water samples. In this regard, five drinking water samples (A-E) were collected from fluoride affected area (Manga Mandi near Lahore) and fluoride removal tests were performed using optimized adsorption conditions.

\section{Results and Discussion}

The general appearance of MIAA was white hard granules as shown in Figure 1(a). The size of the granules varied from 3 to $6 \mathrm{~mm}$. A number of experiments were conducted in order to find the appropriate conditions like adsorbent dose, concentration of fluoride, contact time, and stirring rate $(\mathrm{rpm})$ for the adsorption of fluoride by MIAA. The SEM images of MIAA before and after adsorption showed that there was a considerable change in the surface after adsorption of fluoride ions which were supposed to adhere on the MIAA surface, refer to Figures 1(b) and 1(c).

3.1. Effect of Adsorbent Dose. The effect of MIAA and activated charcoal dose on the fluoride adsorption was carried out at $20 \pm 1^{\circ} \mathrm{C}$. Figure 2 demonstrates that there was an increase in fluoride \% removal by increasing dose of the adsorbents. The increase in removal efficiency with increasing dose was due to the increase in surface area and more active sites were available for adsorption of fluoride. But after a specified adsorbent dose, the percentage of removal did not increase considerably and that dose was considered as optimum dose. The optimum dose was $10 \mathrm{~g} / \mathrm{L}$ for both the adsorbents with the fluoride removal efficiency of $95 \%$ and $84 \%$ for MIAA and activated charcoal, respectively.

3.2. Effect of Contact Time. The effect of contact time on fluoride adsorption is shown in Figure 3. As the contact time increased, the adsorption capacity of both adsorbents also increased. The increase in the adsorption capacity in the first 40 minutes was very rapid. This might be due to the diffusion of fluoride ions into the surface pores of the adsorbents. After 40 minutes, the increase was less rapid probably due to the migration of fluoride ions from upper adsorbent surface to inner pores. MIAA removed most of the fluoride ions around 60 minutes and then attained equilibrium, whereas activated charcoal adsorption reached equilibrium after 90 minutes.

3.3. Effect of Stirring Rate. The influence of varying stirring rate on fluoride removal efficiency of MIAA and activated charcoal is depicted in Figure 4. It was observed that at lower $\mathrm{rpm}$, the removal capacity was low but as the rpm increased, the fluoride removal also increased. This might be due to the better contact between adsorbent and adsorbate at higher rpm. The optimum stirring rates for activated charcoal and MIAA were $125 \mathrm{rpm}$ and $150 \mathrm{rpm}$, respectively.

3.4. Effect of Initial Fluoride Concentration. The effect of increasing fluoride concentration on adsorption capacity of MIAA and activated charcoal is shown in Figure 5. For both adsorbents, the adsorption capacity increased to a specified level then attained equilibrium. The maximum adsorption capacity of MIAA and activated charcoal were $0.76 \mathrm{mg} / \mathrm{g}$ and $0.47 \mathrm{mg} / \mathrm{g}$, respectively, when the initial fluoride concentration $\left(C_{i}\right)$ was $12 \mathrm{mg} / \mathrm{L}$.

3.5. Isotherm Study. The adsorption isotherm is useful in investigating the feasibility of an adsorbent for an adsorbate. The Freundlich and Langmuir isotherms provided deep insight into the adsorption of fluoride on MIAA and activated charcoal, refer to Figures 6 and 7. The values of the adsorption constants $K_{f}, n, K$, and $V_{m}$ are given in Table 1 . The Freundlich model fitted well for both adsorbents with the regression coefficient $R^{2}$ of 0.98 and 0.97 for MIAA and activated charcoal, respectively. $K_{f}$ is the Freundlich constant representing the relative adsorption affinity of the adsorbent toward the adsorbate molecules, and $n$ represents the heterogeneity of the adsorbent. $K_{f}$ value in case of MIAA is almost three times higher as compared to the value for activated charcoal. The value of $n$ for both adsorbents was greater than unity indicating that the amount adsorbed increased less rapidly than the concentration [19]. The nonlinearity of the adsorption isotherms is evident because $n>1$ as shown in Figures 6 and 7. 


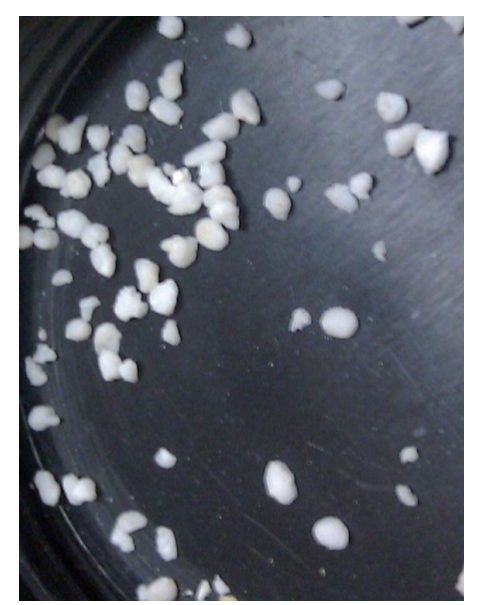

(a)

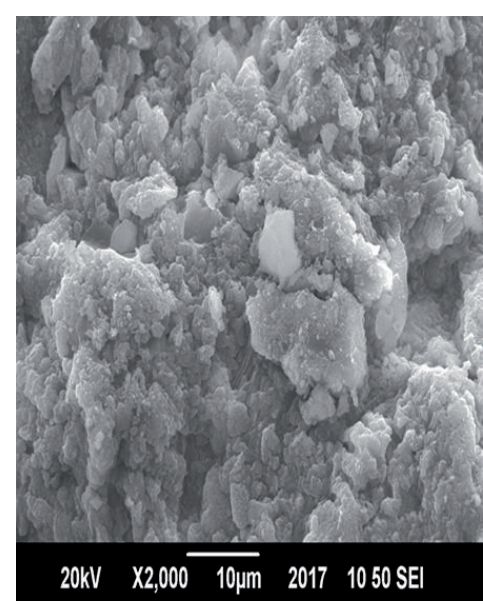

(b)

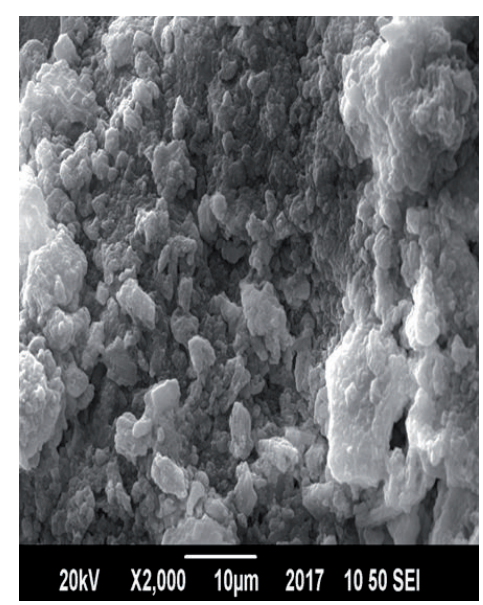

(c)

Figure 1: (a) MIAA, (b) SEM image of pure MIAA, and (c) SEM image of MIAA after adsorption.

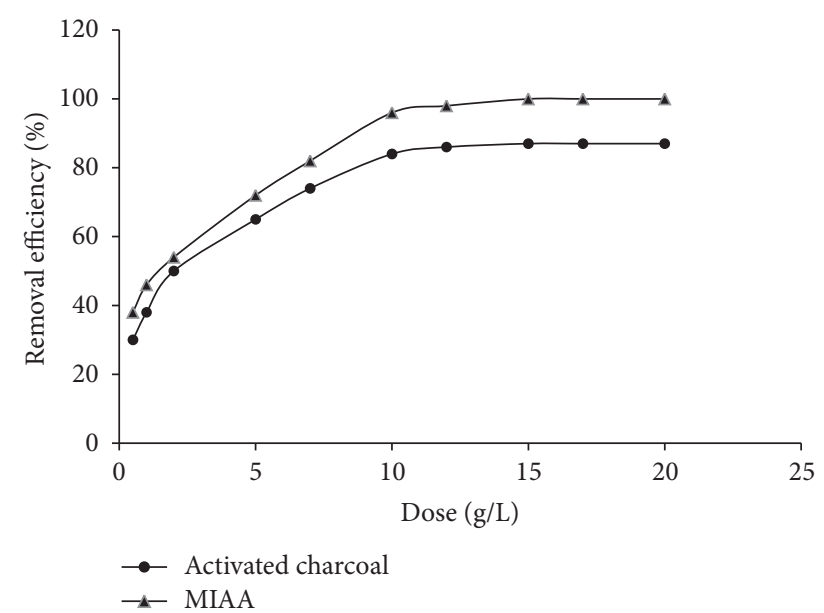

FIGURE 2: Effect of an adsorbent dose on the removal of fluoride at $20 \pm 1^{\circ} \mathrm{C}$.

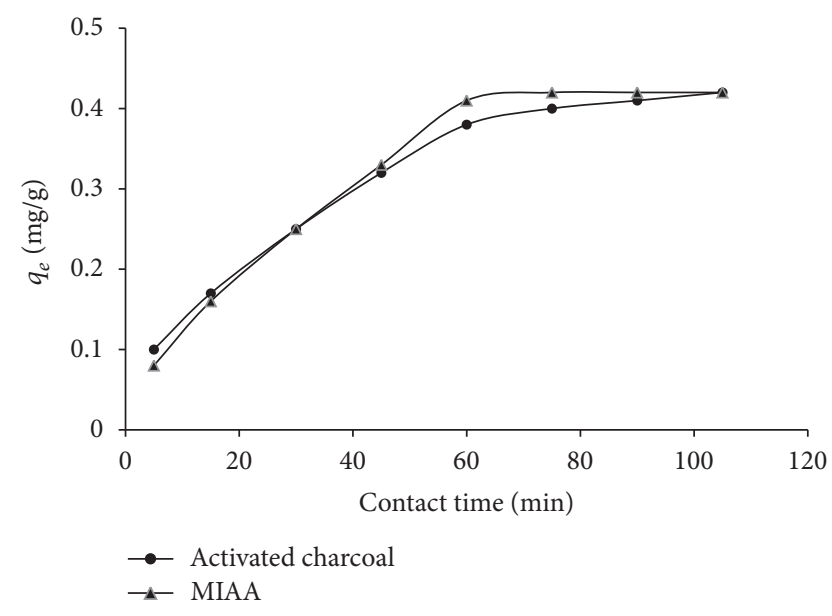

FIgURE 3: Effect of contact time on adsorption capacity of MIAA and activated charcoal at $\left(20 \pm 1^{\circ} \mathrm{C}\right)$.

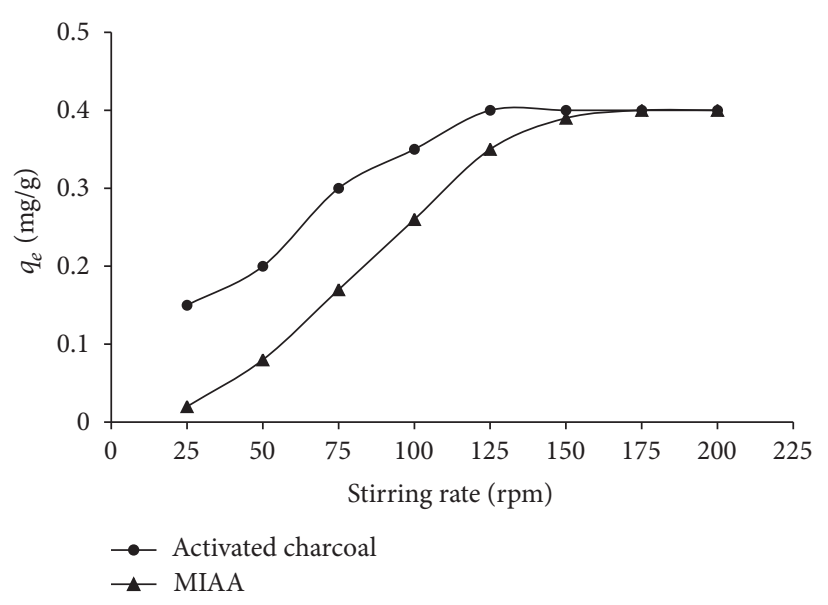

FIGURE 4: Effect of stirring rate on adsorption capacity of MIAA and activated charcoal at $\left(20 \pm 1^{\circ} \mathrm{C}\right)$.

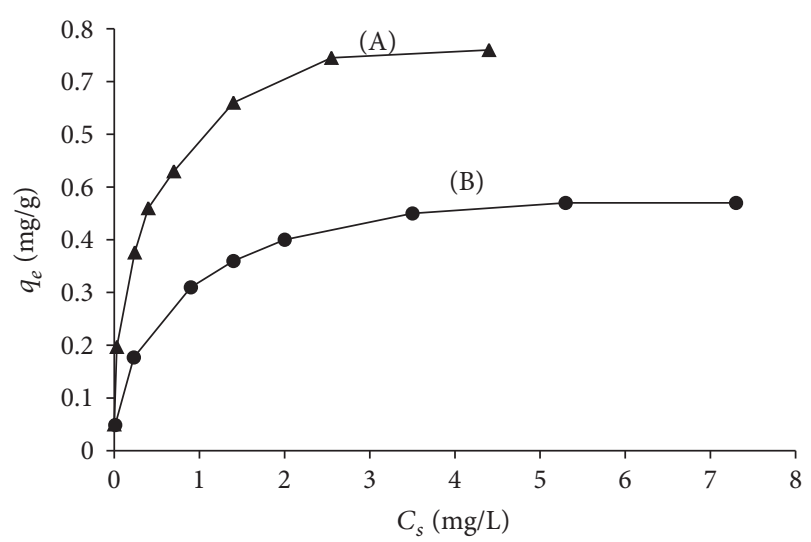

FIGURE 5: Effect of initial concentration of fluoride on adsorption capacity of (a) MIAA and (b) activated charcoal at $20 \pm 1^{\circ} \mathrm{C}$. 


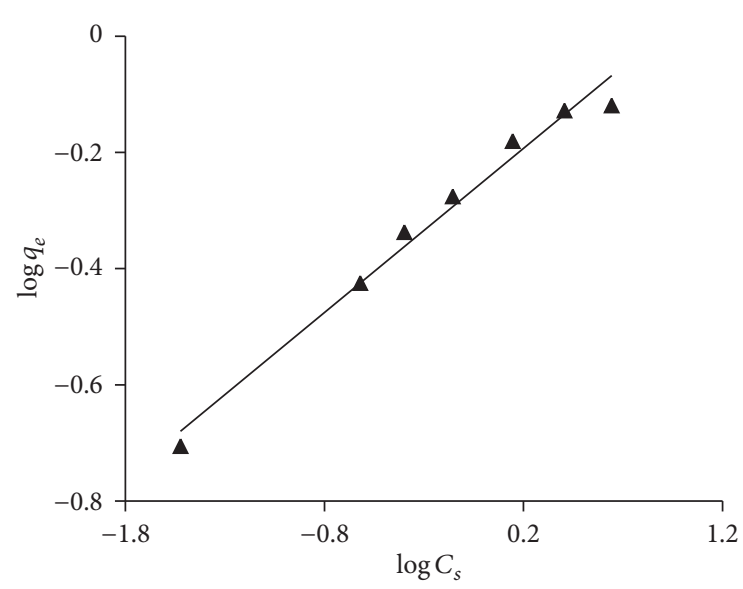

(a)

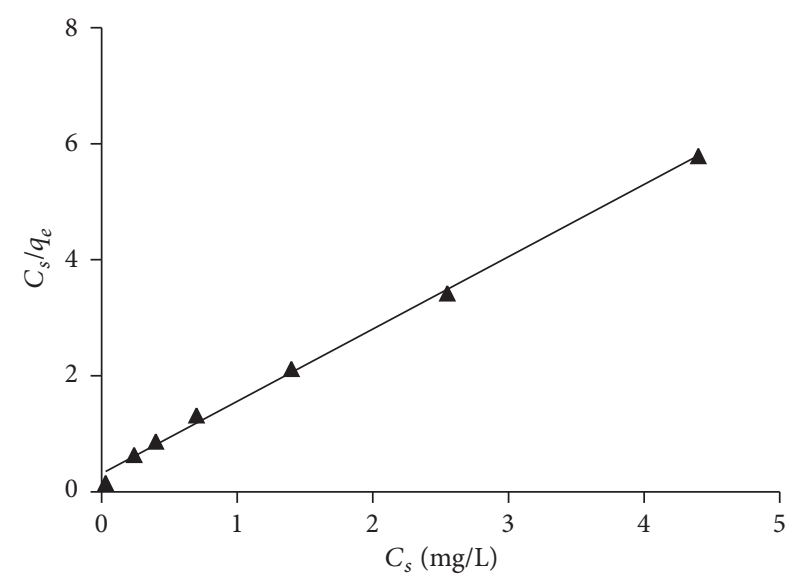

(b)

FIgURE 6: The Freundlich and Langmuir isotherms for fluoride adsorption using MIAA at $\left(20 \pm 1^{\circ} \mathrm{C}\right)$.

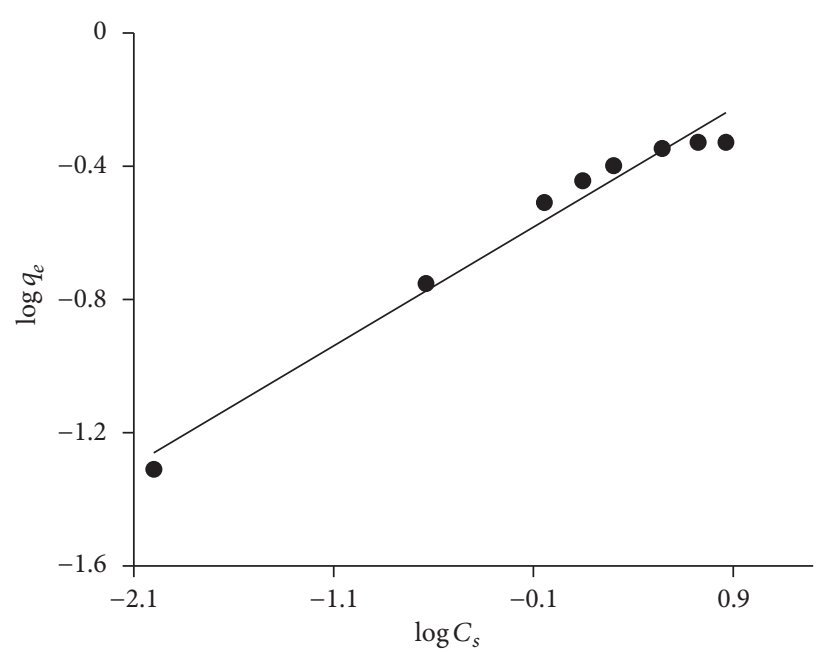

(a)

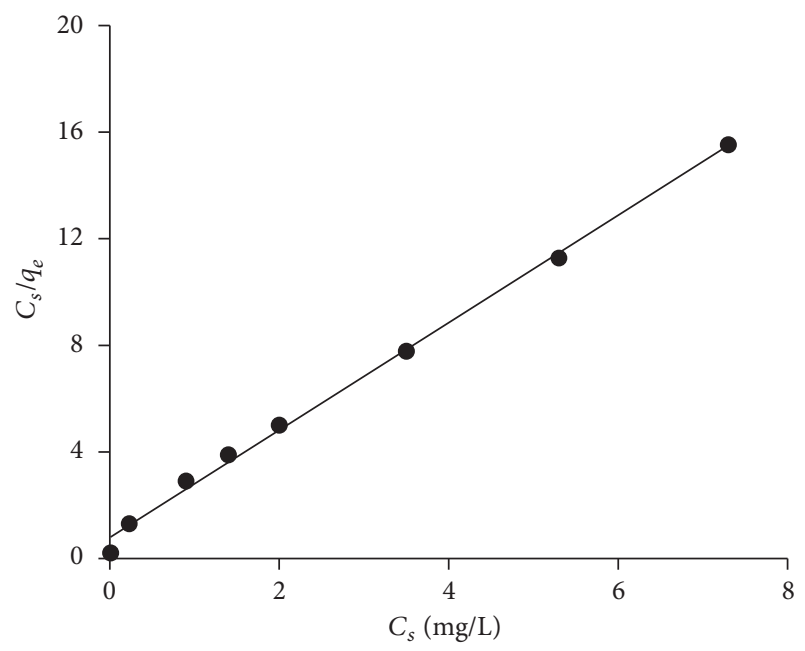

(b)

FIgURE 7: The Freundlich and Langmuir isotherms for fluoride adsorption using activated charcoal at $\left(20 \pm 1^{\circ} \mathrm{C}\right)$.

The Langmuir adsorption isotherm fitted very well for the fluoride adsorption on both adsorbents with the regression coefficient $R^{2}$ of 0.99 as shown in Figures 6 and 7. The values of the adsorption coefficient $K$ and the monolayer capacity $V_{m}$ calculated from the Langmuir equation are given in Table 1 . The values of $K$ and $V_{m}$ are higher for MIAA as compared to values for activated charcoal that indicates that adsorption of fluoride on MIAA is more favorable.

The Langmuir constant $K$ can be used to predict whether an adsorption system is favorable or unfavorable [20]. For this purpose, a dimensionless separation factor $R_{L}$ is generally employed:

$$
R_{L}=\frac{1}{1+K C_{i}}
$$

where $R_{L}=$ dimensionless separation factor, $C_{i}=$ initial fluoride concentration $(\mathrm{mg} / \mathrm{L})$, and $K=$ Langmuir constant.
TABLE 1: Values of Freundlich and Langmuir isotherms constants.

\begin{tabular}{lcccccc}
\hline \multirow{2}{*}{ Adsorbent } & \multicolumn{3}{c}{ Freundlich constants } & \multicolumn{3}{c}{ Langmuir constants } \\
& $K_{f}$ & $n$ & $R^{2}$ & $K$ & $V_{m}$ & $R^{2}$ \\
\hline MIAA & 0.60 & 3.57 & 0.98 & 4.0 & 0.80 & 0.99 \\
Activated charcoal & 0.26 & 2.81 & 0.97 & 2.63 & 0.49 & 0.99 \\
\hline
\end{tabular}
ingly.

The parameter $R_{L}$ indicates the isotherm shape accord-

In this work, the values of $R_{L}$ were in the range 0.02-0.11 against the initial fluoride concentration, $C_{i}=2-12 \mathrm{mg} / \mathrm{L}$ as given in Table 2 . The values of $R_{L}$ suggest that the adsorption of fluoride on MIAA is favorable at $20 \pm 1^{\circ} \mathrm{C}$.

3.6. Regeneration and Actual Water Sample Treatment. Figure 8 describes results of the MIAA regeneration study. In case of thermal regeneration, the removal efficiency of MIAA is up 


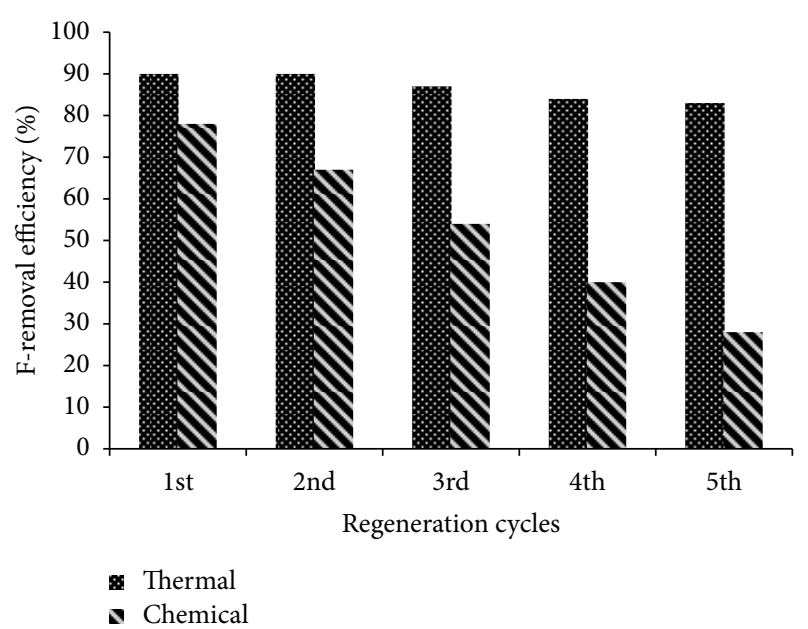

FIGURE 8: Regeneration of MIAA by thermal and chemical processes.

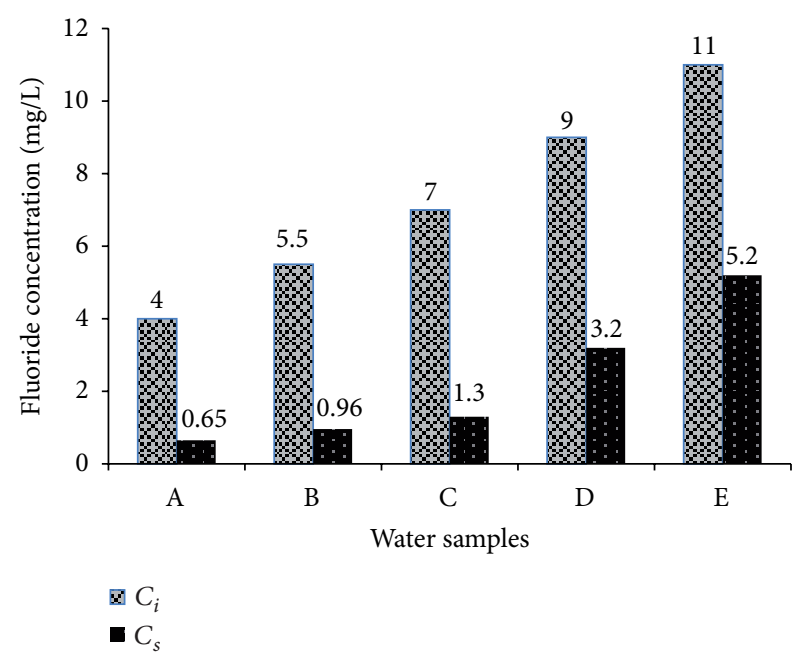

FIGURE 9: Real water samples with initial fluoride concentration $\left(C_{i}\right)$ and final concentration $\left(C_{s}\right)$.

TABLE 2: The value of $R_{L}$ factor and type of isotherm.

\begin{tabular}{lc}
\hline$R_{L}$ & Type of isotherm \\
\hline Greater than 1 & Unfavorable \\
1 & Linear \\
Between 0 and 1 & Favorable \\
0 & Irreversible \\
\hline
\end{tabular}

to $85 \%$ even after 5 th regeneration cycle, whereas in case of chemical regeneration, the efficiency considerably decreased after every cycle. It may be due to vigorous washing of MIAA after soaking in $\mathrm{NaOH}$ in order to neutralize the $\mathrm{pH}$.

Figure 9 demonstrates removal of fluoride from five drinking water samples (A-E) taken from fluoride affected area Manga Mandi using MIAA under optimized adsorption conditions. The matrix of actual samples is complex and there may be several competing ions present in the samples, but still the removal efficiency ranged from 53\% (sample E) to $84 \%$ (sample A). This indicates effectiveness of the MIAA for the removal of fluoride from drinking water.

\section{Conclusion}

Modified immobilized activated alumina (MIAA) has efficiently been utilized for the removal of fluoride from drinking water with the removal efficiency up to $95 \%$ at $20 \pm 1^{\circ} \mathrm{C}$. The adsorption capacity of MIAA was much higher $(0.76 \mathrm{mg} / \mathrm{g})$ as compared to the adsorption capacity of activated charcoal $(0.47 \mathrm{mg} / \mathrm{g})$ for the same concentration fluoride samples. Both the Langmuir and Freundlich adsorption isotherms fitted well for the fluoride adsorption on MIAA with the regression coefficient $R^{2}$ of 0.99 and 0.98 , respectively. MIAA can both be regenerated thermally and chemically. MIAA proved effective for the treatment of fluoride contaminated actual drinking water samples.

\section{Acknowledgment}

The authors thank the National University of Sciences and Technology (NUST), Islamabad, Pakistan for the financial support of this work.

\section{References}

[1] W. Nigussie, F. Zewge, and B. S. Chandravanshi, "Removal of excess fluoride from water using waste residue from alum manufacturing process," Journal of Hazardous Materials, vol. 147, no. 3, pp. 954-963, 2007.

[2] NSDWQ, "National Standards for Drinking Water Quality," Pakistan Environmental Protection Agency, 2008, http:// www.environment.gov.pk/act-rules/DWQStd-MAY2007.pdf.

[3] WHO, "Guidelines for Drinking Water Quality," World Health Organization, 2011, http://whqlibdoc.who.int/publications/ 2011/9789241548151_eng.pdf.

[4] J. Fawell, K. Bailey, J. Chilton, E. Dahi, L. Fewtrell, and Y. Magara, Fluoride in Drinking Water, WHO IWA Publishing, 2006.

[5] UNEP, "Endemic fluorosis: a global health issue, a technical report for the Human Exposure Assessment Locations Project," World Health Organization, Geneva, Switzerland, 1992, http://extranet.who.int/iris/handle/10665/59588.

[6] M. Ahmad, B. Ahmad, S. N. Hussain, and S. Mahmood, "Clinical investigations of skeletal fluorosis in children of Manga Mandi in Pakistan," Pakistan Journal of Pharmaceutical Science, vol. 16, no. 2, pp. 9-11, 2003.

[7] Meenakshi and R. C. Maheshwari, "Fluoride in drinking water and its removal," Journal of Hazardous Materials, vol. 137, no. 1, pp. 456-463, 2006.

[8] I. Ali and V. K. Gupta, "Advances in water treatment by adsorption technology," Nature Protocols, vol. 1, no. 6, pp. 2661-2667, 2007.

[9] Y. Tang, X. Guan, T. Su, N. Gao, and J. Wang, "Fluoride adsorption onto activated alumina: modeling the effects of $\mathrm{pH}$ and some competing ions," Colloids and Surfaces A, vol. 337, no. 1-3, pp. 33-38, 2009. 
[10] K. A. Emmanuel, G. Ramaraju, A. Rambabu, and V. Rao, "Removal of fluoride from drinking water with activated carbons prepared from $\mathrm{HNO}_{3}$ activation-a comparative study," Rasayan Journal of Chemistry, vol. 4, pp. 802-818, 2008.

[11] Y. Sun, Q. Fang, J. Dong, X. Cheng, and J. Xu, "Removal of fluoride from drinking water by natural stilbite zeolite modified with Fe(III)," Desalination, vol. 277, no. 1-3, pp. 121-127, 2011.

[12] S. P. Kamble, S. Jagtap, N. K. Labhsetwar et al., "Defluoridation of drinking water using chitin, chitosan and lanthanummodified chitosan," Chemical Engineering Journal, vol. 129, no. 1-3, pp. 173-180, 2007.

[13] E. Kumar, A. Bhatnagar, U. Kumar, and M. Sillanpää, "Defluoridation from aqueous solutions by nano-alumina: characterization and sorption studies," Journal of Hazardous Materials, vol. 186, no. 2-3, pp. 1042-1049, 2011.

[14] A. R. Tembhurkar and S. Dongre, "Studies on fluoride removal using adsorption process," Journal of Environmental Science and Engineering, vol. 48, no. 3, pp. 151-156, 2006.

[15] S. M. Maliyekkal, A. K. Sharma, and L. Philip, "Manganeseoxide-coated alumina: a promising sorbent for defluoridation of water," Water Research, vol. 40, no. 19, pp. 3497-3506, 2006.

[16] S. S. Tripathy, J. L. Bersillon, and K. Gopal, "Removal of fluoride from drinking water by adsorption onto alum-impregnated activated alumina," Separation and Purification Technology, vol. 50, no. 3, pp. 310-317, 2006.

[17] L. M. Camacho, A. Torres, D. Saha, and S. Deng, "Adsorption equilibrium and kinetics of fluoride on sol-gel-derived activated alumina adsorbents," Journal of Colloid and Interface Science, vol. 349, no. 1, pp. 307-313, 2010.

[18] G. Buelna and Y. S. Lin, "Sol-gel-derived mesoporous $\gamma$-alumina granules," Microporous and Mesoporous Materials, vol. 30, no. 23, pp. 359-369, 1999.

[19] S. Deng, V. Viswanathan, and D. Candelaria, "Sol-gel derived mesoporous alumina for fluoride and arsenic removal from drinking water," New Mexico Journal of Science, vol. 44, pp. 183-202, 2006.

[20] G. Alagumuthu, V. Veeraputhiran, and R. Venkataraman, "Fluoride sorption using cynodon dactylon-based activated carbon," Hemijska Industrija, vol. 65, no. 1, pp. 23-35, 2011. 

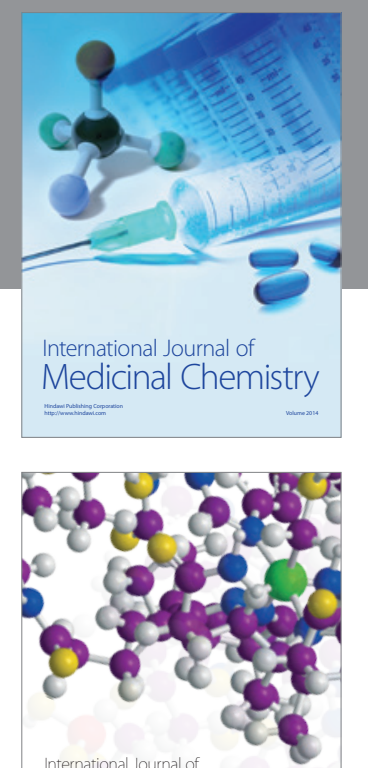

\section{Carbohydrate} Chemistry

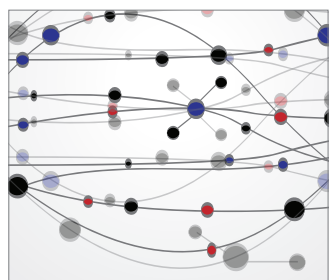

The Scientific World Journal
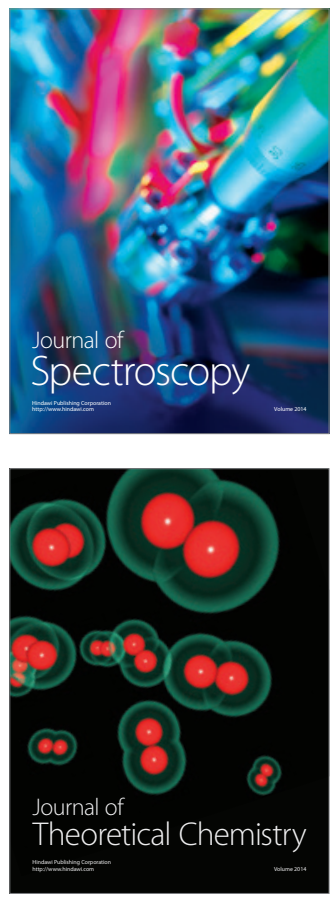
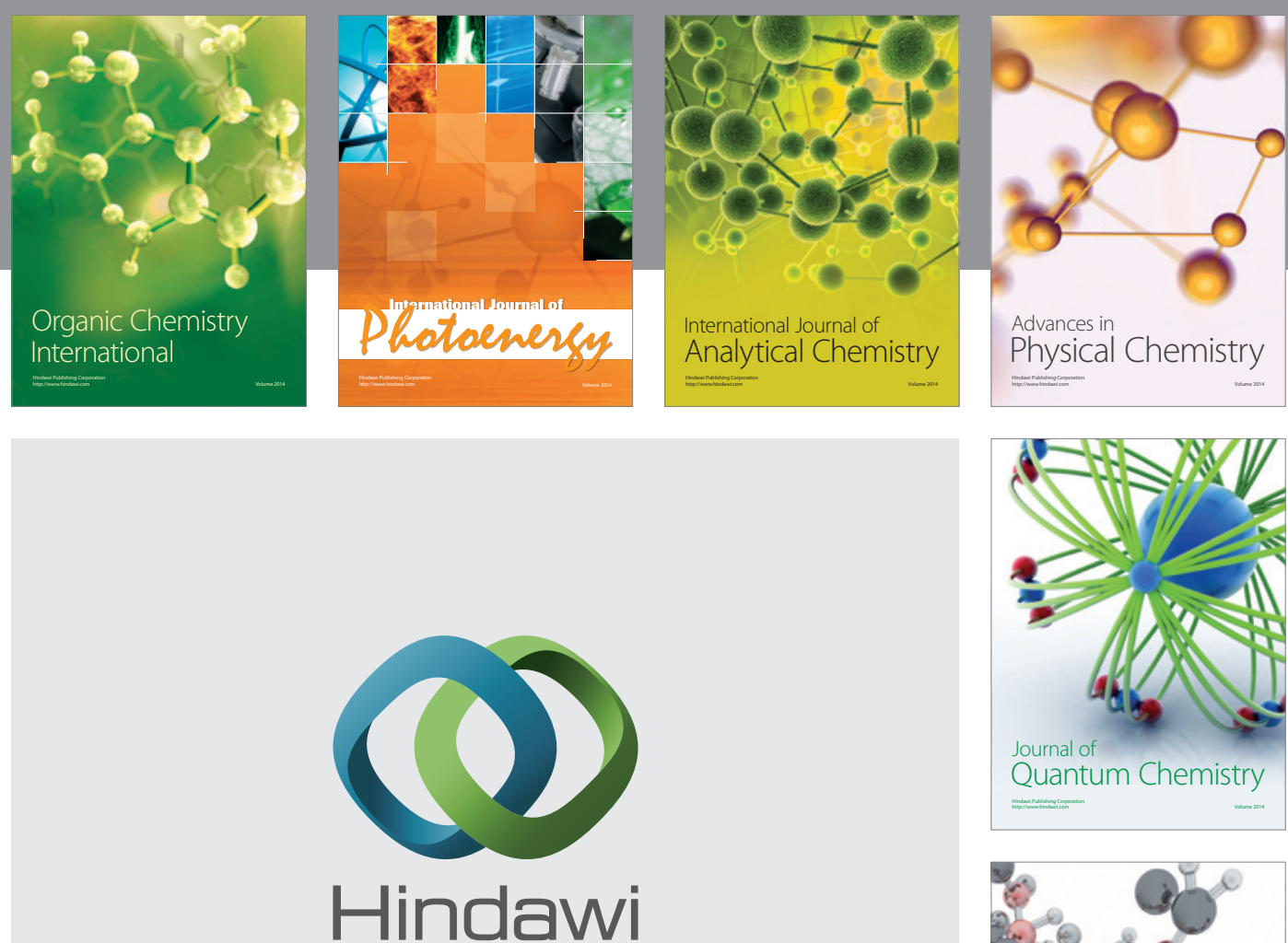

Submit your manuscripts at

http://www.hindawi.com

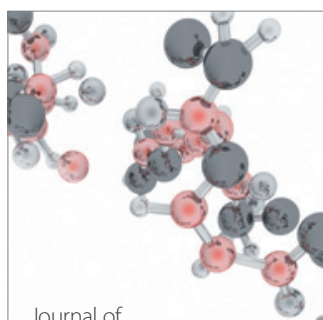

Analytical Methods

in Chemistry

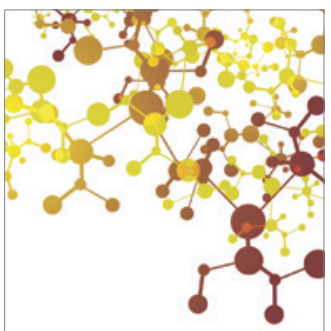

Journal of

Applied Chemistry

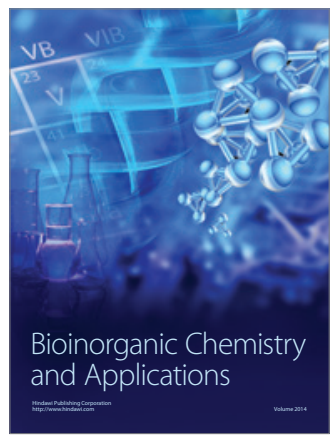

Inorganic Chemistry
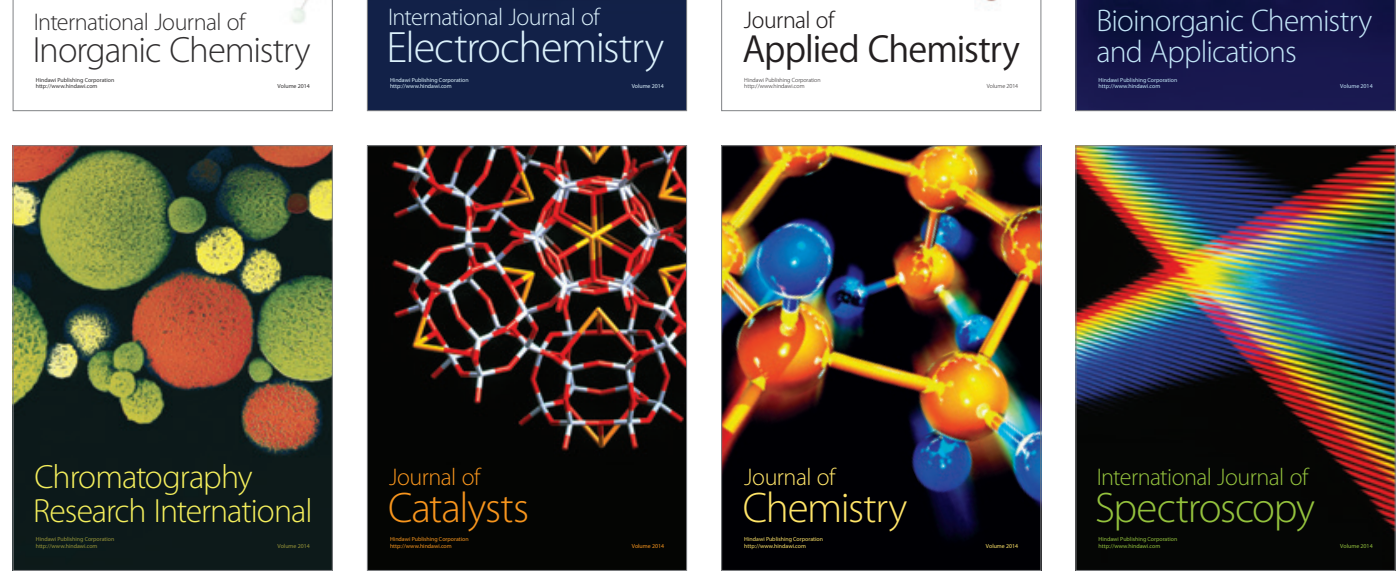